\title{
Appropriate, quality imaging tests through linkage of payment to guidelines, accreditation and training
}

\author{
Barry B. Rubin MD PhD, Bernita Drenth, Rob S.B. Beanlands MD
}

Competing interests:

Barry Rubin is the Chair of

the Expert Panel on

Appropriate Utilization of

Diagnostic and Imaging

Studies, Ontario. Rob

Beanlands is a member of

the expert panel; he has

received consultant fees and

grants from GE Healthcare

and Lantheus Medical

Imaging, and consultant

fees from Jubilant

DRAXImage. Bernita

Drenth provided operational

support for the expert panel.

Barry Rubin and Bernita

Drenth have received

consultant fees from the

Ontario Ministry of Health

and Long-Term Care.

This article has been peer reviewed.

Correspondence to:

Barry Rubin,

barry.rubin@uhn.ca

CMAJ 2015. DOI:10.1503

/cmaj.140638
$\mathrm{T}$ he volume of imaging tests has risen more rapidly than most other drivers of health care costs, with the number of magnetic resonance imaging (MRI) and computed tomography (CT) tests increasing threefold between 1995 and 2010., ${ }^{1,2}$ It is estimated that $10 \%-30 \%$ of imaging tests are done for inappropriate indications; the numbers vary by jurisdiction, modality and referring group. ${ }^{3}$ Inappropriate imaging tests increase costs and wait times and result in unnecessary radiation exposure during CT scans. Conversely, failing to do imaging tests for appropriate indications may lead to underuse and missed diagnosis, with deleterious clinical consequences.

In many jurisdictions, all that is needed for physicians to perform and be compensated for the majority of imaging studies is licensure as a medical doctor and the equipment necessary to do the test. There are few requirements that imaging studies be done for approved indications, or that physicians billing for diagnostic tests have the training or expertise necessary to perform a safe, accurate diagnostic examination. Many laboratories perform imaging tests for approved indications, meet the accreditation standards and have technologists and physicians who are trained to provide quality care. However, not all imaging facilities meet these standards, and in many areas there is no requirement that they do so.

To develop a comprehensive approach for the use of imaging resources, the Ontario Ministry of Health and Long-Term Care formed the Expert Panel on Appropriate Utilization of Diag-

nostic and Imaging Studies in 2012. The panel includes physicians in academic and community practice, within urban and rural settings. ${ }^{4}$ It concluded that appropriate use of imaging tests would be optimized if the use of accepted indications for imaging tests, based on guidelines developed by national or international specialty societies, was linked to payment for these tests. To ensure quality, the panel recommended that mandatory independent accreditation of imaging facilities and minimum training requirements for technologists and physicians performing and interpreting the imaging tests be linked to payment for these tests. These general recommendations and recommendations by the Cardiac Care Network of Ontario regarding the use of echocardiography ${ }^{5}$ have been endorsed by the Government of Ontario and the Ontario Medical Association and await implementation. The panel also recommended that referral and reporting processes for imaging tests be standardized, that regional imaging capacity be planned and coordinated, and that data registries be established to evaluate quality, safety and system effectiveness.

Other strategies have been implemented to increase the appropriate use of imaging tests. The Royal College of Radiologists in the United Kingdom developed the iRefer program to guide physicians regarding the most appropriate investigations for various indications and to inform decisions about commissioning of imaging services. ${ }^{6}$ Similarly, the guidelines for diagnostic imaging referral issued by the Canadian Association of Radiologists help physicians to choose the most appropriate tests. ${ }^{3}$ However, there is no link between the use of the iRefer Program or the referral guidelines and payment to physicians for imaging services.

In the United States and in Canada, the Choosing Wisely campaigns (www.choosingwisely.org, www.choosingwiselycanada.org) encourage physicians, patients and other health care stakeholders to discuss tests and procedures, including imaging tests, that may not be medically indicated and may cause harm. ${ }^{7}$ This is a positive step; however, the campaign's overall impact on 
the use of imaging tests will be limited, because specialty societies have targeted only a small number of imaging services and participation in the Choosing Wisely initiative is optional. ${ }^{8}$ In addition, the campaign does not address other factors that are necessary to realize appropriate, quality imaging tests (e.g., the use of best practices when ordering and interpreting tests, and the assurance of provider competence and facility excellence).

In some instances, the physician ordering an imaging study is the owner of the imaging equipment used to conduct the test. A 2012 US Government Accountability Office report to Congress $^{9}$ noted that financial incentives for self-referring providers, an issue not addressed by the Choosing Wisely or iRefer initiatives, are likely a major factor driving the increase in imaging tests and recommended "payment reduction for self-referred advanced imaging services." Seven Canadian provinces regulate selfreferrals to independent health facilities, and four provinces regulate referrals to health facilities in which immediate family members have investments. The expert panel in Ontario noted that access to imaging studies could be impeded if a financial penalty was applied to imaging tests ordered appropriately by the physician conducting the test, particularly in smaller or more remote communities and in emergency departments. Requiring patients to go back to their primary care physician or other specialist to order an imaging study could delay access to care.

Linking mandatory use of guidelines, independent accreditation of imaging facilities and minimum training requirements for health care professionals who perform and interpret imaging tests to payment should promote appropriate use and increase the quality of imaging tests. Reducing the number of imaging tests for inappropriate indications will decrease wait times for tests ordered for appropriate indications and will improve the efficiency of health care systems. Linking the use of guidelines to payment for imaging tests would eliminate the need to impose financial penalties on self-referred services, as recommended by the US Government Accountability Office, and would respect the judgment of the physicians who order the imaging tests.

Establishing the human resources and infrastructure necessary to confirm adherence to guidelines when ordering imaging tests and to validate the accreditation and training status of laboratories and individuals performing these tests will be associated with new costs for some health care systems. However, we believe that these costs will be substantially less than the savings that would be realized by eliminating payments for unnecessary imaging tests. Spending on diagnostic imaging in Canada now exceeds $\$ 2.2$ billion annually; ${ }^{10}$ reducing the number of unnecessary imaging tests by $10 \%$ would save $\$ 220$ million per year. It seems unlikely that the cost of monitoring the use of guidelines and mandating accreditation and minimum training requirements would approach the cost of these potential savings.

Health care professionals should focus on ensuring that imaging tests are done for the right reasons, in a timely fashion, and in an appropriate and safe environment by properly trained providers. This strategy should lead to more appropriate use, increased quality of imaging tests and increased value for patients and health care systems.

\section{References}

1. Medical imaging. Ottawa: Canadian Institute for Health Information. Available: www.cihi.ca/cihi-ext-portal/internet/en /tabbedcontent/types+of+care/specialized+services/medical +imaging/cihi010642?wt.ac=sp_mit_20120320_e (accessed 2014 June 27).

2. Smith-Bindman R, Miglioretti DL, Johnson E, et al. Use of diagnostic imaging studies and associated radiation exposure for patients enrolled in large integrated health care systems, 19962010. JAMA 2012;307:2400-9.

3. Fraser J, Reed M. Appropriateness of imaging in Canada. Can Assoc Radiol J 2013;64:82-4.

4. Expert Panel on Appropriate Utilization of Diagnostic and Imaging Studies. Toronto: Ontario Ministry of Health and LongTerm Care; 2013. Available: www.health.gov.on.ca/en/news/ bulletin/2012/hb_20120727_1.aspx (accessed 2014 June 24).

5. Standards for provision of echocardiography in Ontario. Toronto: Cardiac Care Network; 2012. Available: www.ccn.on .ca/ccn_public/uploadfiles/files/CCN_ECHO_Report_2012.pdf (accessed 2014 June 30).

6. iRefer guidelines: making the best use of clinical radiology. London (UK): Royal College of Radiologists. Available: www .rcr.ac.uk/content.aspx?PageID=995 (accessed 2014 June 28).

7. Cassel CK, Guest JA. Choosing Wisely: helping physicians and patients make smart decisions about their care. JAMA 2012; 307:1801-2.

8. Morden NE, Colla CH, Sequist TD, et al. Choosing wisely The politics and economics of labeling low-value services. N Engl J Med 2014;370:589-92.

9. Cosgrove JC. Medicare: higher use of advanced imaging services by providers who self-refer costing medicare millions. Washington (DC): US Government Accountability Office; 2012. Available: www.gao.gov/assets/650/648988.pdf (accessed 2014 June 24).

10. Medical imaging in Canada, 2007. Ottawa: Canadian Institute for Health Information; 2012. Available: https://secure.cihi.ca /free_products/MIT_2007_e.pdf (accessed 2014 June 30).

Affiliations: Division of Vascular Surgery (Rubin), Peter Munk Cardiac Centre, Toronto General Hospital and University Health Network; Department of Surgery (Rubin), Faculty of Medicine, University of Toronto; Drenth Consultants Inc. (Drenth), Toronto, Ont.; University of Ottawa Heart Institute (Beanlands), Ottawa, Ont.

Contributors: All of the authors contributed substantially to the preparation of this manuscript, have approved the final version submitted for publication and have agreed to act as guarantors of the work. 